\title{
Captive Subjects: Pharmaceutical Testing and Prisoners
}

\author{
Timothy J. Wiegand, MD
}

University of California and the California Poison Control Center, San Francisco.

The debate about using prison inmates for medical testing has again surfaced. A federal panel of medical advisors from the Institute of Medicine (IOM) of the National Academy of Sciences has recommended that the government loosen restrictions limiting testing of pharmaceutical agents on prisoners [1]. Current regulations, passed in 1978, allow prison inmates to participate in federally financed biomedical research if the experiments pose no more than "minimal" risks to the subjects. The IOM report advises, however, that experiments with greater risk be permitted if they have the potential to benefit prisoners. Additionally, while current regulations only cover federally funded prison research, the new recommendations also advise the inclusion of privately funded research. The new recommendations would include individuals on probation and parole-increasing the overall number of "prisoners" effected by these regulations from 2 million to nearly 7 million.

The current regulations (regarding the use of prisoners as subjects in pharmaceutical research) were created in response to revelations of harmful and coercive practices that occurred in prison research conducted during the1950s and through 1970. This was a period of increased awareness of abuse in prisons, and with it came revelations regarding the treatment of the subjects in the Tuskegee Study of Untreated Syphilis in the Negro Male. The climate was right for increased oversight and regulation. A recent New York Times editorial, written in response to the IOM report, further discusses this context and highlights specific instances and institutions where abuse was rampant [2].

“Until the early 1970's, about 90 percent of all pharmaceutical products were tested on prison inmates, federal officials say. But such research diminished sharply in 1974 after revelations of abuse at prisons like Holmesburg here (highlighted in the New York Times article), where inmates were paid hundreds of dollars a month to test items as varied as dandruff treatments and dioxin, and where they were exposed to radioactive, hallucinogenic and carcinogenic chemicals."

Historically, isolated and sporadic episodes of the use of prisoners as study subjects for pharmaceutical research existed before World War II, yet it was wartime medical projects that fully launched prison-based research. In 1944 hundreds of prisoners in the state of Illinois consented to infection with malaria as researchers searched for new and more effective ways to prevent and treat tropical diseases that ravaged the Allied forces in the Pacific. In response to these experiments, a committee was created to analyze the ethics of prisoners as research subjects. This committee subsequently pronounced the experiments "ideal" in their conformity to the American Medical Association (AMA) rules concerning human experimentation. The findings, then, were published in the nation's leading medical journal, the Journal of the American Medical Association (JAMA) [3]. This publication signified acceptance of prison-based research by the medical community. After this publication the use of prisoners in research gained such momentum that (until the early 1970s) nearly all trials involving investigational new drugs were conducted on prisoners [4].

Currently, there is a significant demand for pharmaceutical testing. From 1995 to 2005, the contract research industry, grown out of the increasing need for subject recruitment for clinical trials, has grown from a 1 billion to a 7 billion dollar-per-year industry. Along with increasing testing needs has come high profile cases of drug toxicity, and these cases have created increased public awareness about the need for study and surveillance of drug toxicity. For example, it has been suggested that increased testing of Vioxx ${ }^{\mathrm{TM}}$ would have prevented the delay in discovering its cardiovascular toxicity [5].

Despite calls for increased testing, the pharmaceutical industry was not involved in prompting the IOM recommendations.

Notes: Funded by NRSA Grant T32 GM0075456. 
Interestingly, even prior to the FDA's proposal in the 1970s regarding a change in regulations for using prisoners in drug testing, the pharmaceutical industry was turning to the private sector for subject recruitment. They found sufficient numbers of experimental subjects by recruiting students and the poor. The growing controversy regarding the ethics of prisoner use also influenced their decision, yet it was mainly expediency and not the ethical considerations that influenced their decision. In an Advisory Committee on Human Experiments Report regarding pharmaceutical research in prisoners, an administrator associated with an Eli Lilly testing operation at an Indiana prison stated the "reason [they] closed the doggone thing down was that [they] were getting too much hassle and heat from the press. It just didn't seem worth it" [4].

Although the current recommendations call for expanded use of prisoners in research, the IOM authors say they have also written safeguards into their recommendations that will prevent past abuses from occurring in the future. One change recommended by authors of the IOM report allows for prisoners to take part in federally financed clinical trials that only occur in the later, safer, clinical phases. They also recommend that at least half of the subjects in any given trial be non-prisoners, thus allowing for parity in the recruitment to test products that may be more "frightening" to volunteers. Finally, where current research in prisons is only regulated if funded federally-under the proposed regulations all research using prison inmates (regardless of the funding) would be regulated.

Although the proposed changes include provisions intended to prevent the abuses that plagued the previous programs, many prison rights advocates worry that the system would continue to be fraught with potential for abuse. Central to this concern is the debate regarding whether prisoners can truly make uncoerced decisions. The role of financial remuneration in this process raises concerns. When prisoners can earn up to $\$ 1500.00$ a month by participating in pharmaceutical research, and the only other jobs pay 15 to 25 cents a day, officials are concerned this establishes a coercive environment. As evidence for concern, prisoner advocates cite the shortages of basic medical necessities in prison medical facilities. If prisoners cannot get basic necessities like antibiotics or high-blood pressure medication, it seems foolish to suggest that they would benefit from access to cutting-edge therapy and expensive medications by consenting to serve as research subjects. In this resource poor environment, prisoner advocates worry that prisoners may simply enroll in research to gain access to the medical system. California, with some of the nation's largest prisons (which have been subject to severe overcrowding), has already announced that it will not allow the use of prisoners in experiments [6]. Some scientists and physicians who participated in the previous experiments agree, and they worry that any access into the prison system produces an environment ripe for abuse. Even though suggested regulations provide for increased oversight of prisoners involved in clinical trials, some scientists worry that free and informed consent remains a valid issue.
While prisoner rights are central to the debate, oversight remains a significant concern. In 2000, several universities were reprimanded for their use of federal money after conducting hundreds of projects on prisoners but not fully reporting the experiments to the appropriate officials. Many are concerned that supervision, while difficult to conduct in the current environment, would be even more difficult with additional freedom to perform clinical research on prisoners.

Other scientists do not share this belief; however, they believe the benefit to public health outweighs any risk for abuse. Dr. Albert Kligman, currently an emeritus professor of dermatology at the University of Pennsylvania Medical School and former director of the experiments at Holmesburg prison, is quoted in the New York Times article. He cites breakthroughs such as Retin A -an anti-acne drug, and ingredients for the creams and salves to treat poison ivy as evidence of public benefits from prison studies. While confirming that various dangerous substances were used on prisoners during his days as director of experiments at Holmesburg prison, he believes that substances were always administered in low doses and in a careful manner so as to minimize harm. A current member of the ethics committee at Penn, he has stated that he still does not see "anything wrong with what [they] were doing" $[2,7]$.

Interestingly, the use of prisoners as research subjects has been mostly an American phenomenon. Other countries basically did away with this practice after the development of the Nuremburg Code. The first clause of the Nuremberg Code begins with the assertion that the only acceptable experimental subjects are those who are "so situated as to be able to exercise free power of choice." From abroad, it is viewed that the United States has a fairly loose interpretation of this clause.

Ernest D. Prentice, chair of the Department of Health and Human Service Agency's advisory committee, discusses the impact of the IOM recommendations in a Philadelphia Inquirer article. He says that changes, if any, are still a long time coming [8]. What remains to be seen is whether we can learn from the mistakes of the past.

\section{REFERENCES}

1. Ethical Considerations for Research involving Prisoners. Committee on Ethical Considerations for Revisions to DHHS Regulations for Protection of Prisoners Involved in Research. Board on Health Sciences Policy. Editors: Gostin, L. O., Vanchieri, C. and Pope, A. Institute of Medicine of the National Academies. National Academy Press, Washington D.C.; 2006.

2. Urbina, I. Safe drug testing in prisons. The New York Times 13 August, 2006, A22.

3. "Ethics Governing the Service of Prisoners as Subjects in Medical Experiments: Report of a Committee Appointed by Governor Dwight H. Green of Illinois," Journal of the American Medical Association 136 (14 February 1948): 457-458.

4. Advisory Committee on Human Radiation Experiments 
Report (ACHRE Report). Chapter 9.) Prisoners: A Captive

Research Population. Available from: http://www.eh.doe.gov/ ohre/roadmap/achre/index.html

5. Roth R. Clinical trials in the wake of Vioxx: requiring statistically extreme evidence of benefit to ensure the safety of new drugs. Circulation 2006; 113(18): 2253-9.
6. Loewenberg, S. US advisory panel revisits prison research rules. The Lancet 2006; 368(9542): 1143-4.

7. Urbina, I. Panel suggests using inmates in drug trials. The New York Times 7 August, 2006; A1, A21-.

8. Falik, D. Experiments on prisoners recommended - with limits. The Philadelphia Inquirer. 13 July, 2006. 